\title{
Symbolism of Mirrors as the First Step of Individuation and Self-Awareness
}

\author{
Yeo Reum, Lee*
}

\begin{abstract}
$<$ Abstract $>$
This study analyzed the symbolic meanings of mirrors from the viewpoint of analytical psychology. This paper describes various symbolisms of mirrors that appear in eastern and western myths, fairy tales and other literature, and hence analyzes their symbolic meanings in sandplay therapy. Mirrors are significant objects that have existed throughout the history of mankind. In ancient East, mirrors were regarded as sacred objects having magical powers. They also symbolize water, in that they reflect the world and self, or the enlightened psyche. At the same time, however, they sometimes symbolize arrogance and vanity. Mirrors trigger self-awareness. Looking into our own unconscious enables us to become aware of the shadow and the persona, bring them to consciousness, and advance toward individuation. In other words, mirrors are closely related to human self-awareness and the following psychological and emotional elements, the concept of which is related to concept of individuation in analytical psychology.
\end{abstract}

Keywords : symbol, mirror, sandplay therapy, individuation, self-awareness

\footnotetext{
* Play therapist, Goyang Areum Counseling Center for Children and Adolescents (leesummer723@hanmail.net)
} 
Journal of Symbols \& Sandplay Therapy, Vol.9 No.1.

\section{I . Introduction}

An actor appeared in a dream of a woman in her 20s. The actor, surrounded by his fans, was signing out autographs. Upon noticing the dreamer, the actor repeatedly called her over, claiming he had something to give to her. However, the actor could not approach the dreamer as he was surrounded by his fans. When the dreamer asked the actor what it was that he had to give her, his reply was "a mirror." The dreamer awoke from her dream without having received the mirror. From this dream, the dreamer needed to reflect on why she needed a mirror and the significance behind it.

A mirror reflects the shape of an object using the reflection of light. In the past, mirrors were made by refining bronze or copper. Because it was difficult for common people to have access mirrors, they had to look at their reflections in the water, which is how the word mirror (geo-ul in the Korean language) was originated. Because reflections in water are upside-down, the archaic word for upside-down (geo-kku-ro) was geo-u-ru, which later became the word mirror, or geo-ul, used to day after eliminating homophony (Kim, 2015).

In modern society, we can easily access mirrors in our everyday lives thanks to the invention of glass mirrors. We are exposed to mirrors numerous times each day: when we wake up in the morning, in an elevator, after a meal, in the shower, or even in a car. We adorn our faces and straighten out our outfits through the reflection in the mirror. In this process of recognizing and grooming oneself, we are confronted by a reflection of ourselves in the mirror. But we do not have the ability to recognize our reflections in a mirror from the moment we are born; studies show that human beings begin to recognize themselves in a mirror 18-24 months after birth (Cho, 2006). Once we begin to recognize ourselves in a mirror, we begin to look not only at our physical images but also inner world. Furthermore, we become aware of how others look at us. Understanding oneself is crucial in the understanding of others.

The mirror is an historic object that is often portrayed as an important symbol in mythology or in works of art such as paintings and poems, as well as in today's advertisements and movies. In ancient Korea and China, the mirror was not only used as a cosmetics tool, but also regarded as a sacred object with shamanistic powers. It was also used 
in ancestral rites and symbolized the authoritative power of a ruler (Glossary of Cultural Criticism, 2006). A mirror, as it reflects the world and the self, holds a symbolic meaning of water and is also related to the myth of Narcissus (Glossary of Cultural Criticism, 2006). In Buddhism the mirror symbolizes a pure soul, the reflected truth, and an enlightened spirit, while in Taoism it symbolizes self-awareness (Cooper, 1978).

The mirror allows one to see oneself, even parts of oneself that are usually not seen. In other words, it makes one realize one's persona and the shadows, the unknown aspects of one's inner world, in the unconscious. The persona is not what one is to oneself, but rather how one presents himself or herself in front of others. The shadow represents the darker side of "me": my alter ego that resides in the unconscious (Lee, 1998). Even though we are constantly exposed to mirrors in our daily lives, we see our reflections on them with intention. Likewise, the realization of the persona and the shadow would have to be made conscious through self-awareness. In The Way of the Dream, Von Franz explains that "reflection" signifies looking back on oneself in search of one's identity, and that it is the mirror that provides the possibility of seeing oneself as one really is (Boa, 1998). To objectively realize one's true self also involves the realization of one's emotions. The realization of emotions occurs gradually as the inherent lion, anthropoid, and human figures become divided, evoking primal anxiety and unfamiliarity which captivates the ego with an unknown fear (Han, 2013). Because the mirror is a symbolic object that differentiates the most fundamental ego and the alter ego in a human being (Choi, 2016), it becomes a symbol of wisdom that allows us to achieve self-awareness.

On the other hand, the mirror also symbolizes arrogance, vanity, and futility (Choi, 2005). Since reflections show the inverted image of an object, we see distorted versions of that object. If we cannot distinguish the 'me' within the mirror from the real 'me,' we will end up losing ourselves like Narcissus. In other words, identifying to the 'me' within the mirror could be dangerous. This applies to personas. If one severely identifies with the persona, the ego will lose its relationship with its inner psychic world (Lee, 1998).

As explained above, the mirror is closely related to humans' self-awareness and the resulting psychology and emotions, which is related to individuation in the context of analytical psychology. This paper thus explores the symbolism of the mirror within the framework of 
Journal of Symbols \& Sandplay Therapy, Vol.9 No.1.

analytical psychology.

\section{П. SYMBOLISM OF THE MIRROR}

\section{A. The Mirror in Western Mythology}

When Perseus had a mission to cut off Medusa's head, he knew that he could not face her directly as Medusa's gaze turned people to stone. Thus Perseus viewed Medusa's reflection in his polished shield, which was given to him by Athena, and beheaded Medusa as she had a look at herself reflected image. While the mirror was a symbol of wisdom for Perseus, it made Medusa realize that she was no longer the beauty she once was, but an abomination due to her punishment. According to Jung (1964/1966), the mirror represents Perseus' shield that reflected Medusa's image.

Narcissus, a young man known for his beauty, fell in love with his own reflection in the water and drowned in an effort to get close to his reflection. A narcissus flower bloomed where he died. In other words, Narcissus drowned in water because failed to recognize that it is him who was reflected in the water. Water represents the unconscious, and falling into the water signifies the need to be aware of one's unconscious elements. The awareness of one's unconscious elements is an essential process for individuation. Narcissism, named after Narcissus, brings about social maladjustment as a result of excessive self-love and self-intoxication (Kwon, 2014). Narcissistic patients "self-alienate," where they see themselves as strangers as they can never reach their true selves (Bärbel, 1991/2006).

As seen from above, the mirror holds various symbolisms in western mythology. Venus and Narcissus were mesmerized by their reflections in the mirror and embellished themselves. Focusing on embellishing one's outward appearance or being mesmerized by oneself may result in losing one's true self. Failing to maintain a balance between the outer world and the inner world could impede unconscious elements from becoming integrated. Humans can only see themselves through a "mirror." In European languages, there are two expressions: "in the mirror" and "through the mirror." The fact that there is no distinction between the two may 


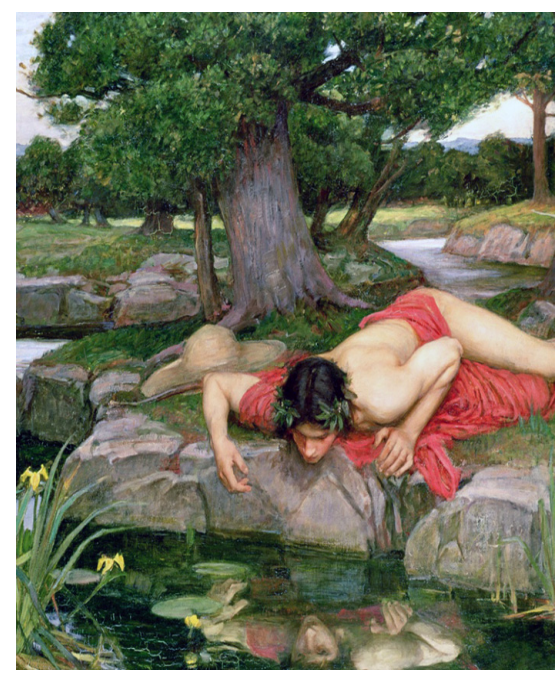

(Source of the photo: http://blog.naver.com/sjwarttalk/60109340830)

Fig. 1. John William Waterhouse - "Echo and Narcissus"

imply that there is no clear distinction between reality and an image, or even a subject and an object (The Great Encyclopedia of Religious Science, 1999). That is why we need to be able to distinguish the two, and enable the conscious to take interest in the unconscious.

\section{B. Mirrors in Eastern Mythology}

According to Korea's Dangun mythology, when the ruler of the heavens Hwanin sent his son Hwanung to the earth to rule the people, he gave Hwanung cheonbuin (proof of descent). According to the Memorabilia of the Three Kingdoms, the cheonbuin consisted of three objects: a bronze dagger, a bronze mirror, and a bronze bell. At the time, a mirror was not an object to reflect oneself off of, but a symbol of authority of the ruling class. It was also a symbol of the magical ability to communicate with nature, as well as a tool used in shamanistic practices to communicate with gods (Korea Creative Content Agency, 2007). Used in religious ceremonies, the mirror signified the place where the gods would descend as its circular shape signified the skies or the sun. High priests would wear a bronze mirror around their neck to reflect the skies and the sunlight, and use it as a tool to emanate their authority 


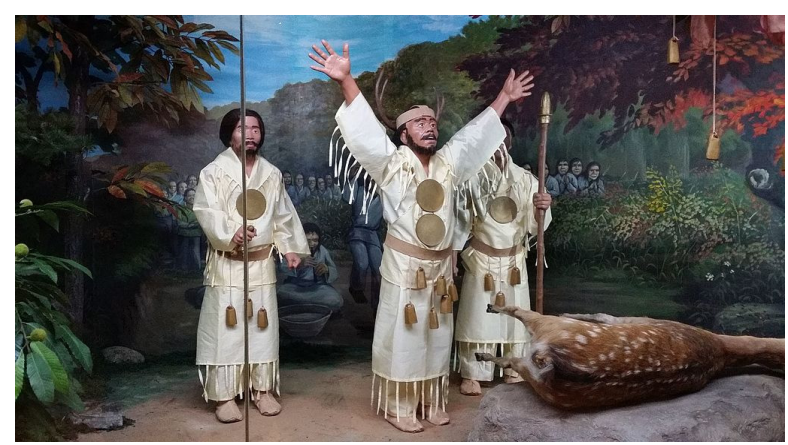

(Source of the photo: https://commons. wikimedia.org/w/index. php?curid=42579669)

Fig. 2. People engaged in an ancestral ritual with bronze mirrors on their chest

and connect themselves with gods. The sun, which overlooks all things, symbolizes gods and their powers (Cooper, 1978). Reflecting the sunlight with the mirror means that the priest illuminates his heart as bright as the sun to shine upon all things. Illuminating one's heart signifies going into one's inner world, integrating the light and the darkness within, and advancing towards the gods. Advancing towards the gods requires courage, as it is the process of recognizing and integrating one's inner ugliness and dark aspects. Through the fundamental light within our unconscious we are able to become conscious of our shadows and personas.

According to Buddhism, humans are judged for 49 days in the afterlife and during the judgment they are faced with seven mirrors that reflect the good and evil doings carried out in their lifetime (Kwak, 2003). The King of the Underworld looks through these mirrors take sinners to hell, while reincarnating those who were virtuous.

The mirror also appears in Japanese mythology. Amaterasu Okami, the goddess of the sun, was born from the left eye of Izanagi, the creator of the Onogoro Island - one of the first-created lands. She dominated the sky realm, Takamanohara. She was then harassed by her younger sibling, so she hid in a cave. To make her come out of hiding, the other gods created a mirror (Yata no Kagami). Amaterasu, curious to see her reflection in the mirror, came out of the cave. This tale is also interpreted as a process of an initiation where Amaterasu Okami becomes a mature woman (Atsuhiko \& Noriko, 1996/2005). Amaterasu's hiding in a cave was an essential process for her individuation. By regressing to the early stage where she identifies with her Self and the ego, she experienced a symbolic death (Jung, 
1964/1966). Amaterasu did not recognize the mature woman in the reflection and came out of the cave to take a closer look, and was enlightened. If Amaterasu had not been intrigued by her new appearance and stayed in the cave, she would have never been able to leave the cave out of fear.

If we don't look at mirrors consciously in our everyday lives, we will not be able to recognize ourselves. This also applies to our shadows and personas. Without looking into them with curiosity, we won't be able to recognize them and would only maintain the status quo. Only through initiation can we continue to our next phase. The myth goes on to say that the mirror, along with the other "Imperial Regalia" of Japan - the sword and the jewel - was passed down to Hono Ninigi, the grandson of Amaterasu who had descended to rule the lands, and became a treasure symbolizing the royal authority of the Japanese imperial family. In this sense, the mirror also symbolizes sacredness. This is analogous to the aforementioned bronze mirror from the Dangun mythology.

A mirror is a symbol of authority and ruler in Eastern mythology. Rulers saw their mirrored images to reflect on themselves during rituals like the ancestral rite. They believed that by exploring their inner world, they could abstain from abusing their power and instead use it to take care of the people. Exploring one's inner world would mean that they would recognize unrealized aspects in the unconscious and bring them to consciousness. But looking into the unconscious and accepting the shadows and personas are never an easy task, and does not happen at once. Only those who can accept what is in the unconscious are able to reach individuation. As human, we should be able to utilize the energy from archetypes through the process of accepting shadows and personas within our unconscious.

\section{Mirrors in Fairy Tales}

"Mirror, mirror, on the wall, who's the fairest of them all?" asks the Queen to the mirror every day in the fairy tale of Snow White. The truth-speaking mirror's consistent reply is "Snow White." The Queen is an embodiment of the narcissism, self-indulgence, and self-love (Eugen, 1981/2003). These women were never taught how to assess themselves correctly; they fail to acknowledge their flaws, falling into either extreme superiority or depression as their 
Journal of Symbols \& Sandplay Therapy, Vol.9 No.1.

self-esteem collapses. The Queen is faced with the fact that someone else is better than her, not realizing the fact that Snow White is another aspect of herself in her inner world. She therefore tries to kill Snow White. The collapse of self-awareness created anxiety in the conscious, and this anxiety leads to an obsessive search for the ego. Because this ego exists in reality only when it is viewed as worthy by others, the ego cannot be in a state of stability where there is a reconciliation between "its intrinsic existence" and "its existence as viewed by others" in a situation where its beauty is denied (Eugen, 1981/2003). In other words, the Queen is in a state where her ego and persona are not differentiated, and where she cannot accept her shadows. Amid all this, the mirror consistently speaks the "truth." A healthy self-love starts from the proper assessment of oneself with a realistic standard; people with healthy self-love fully understand their strengths while respecting their limits at the same time (Bärbel, 1991/2006). In this fairy tale, the mirror symbolizes an authentic self-awareness. Furthermore, because the mirror reflects entities objectively, it symbolizes the power of the unconscious that makes entities conceive thoughts about themselves that they have never formulated before (Han, 2016). Standing in front of a mirror is not enough to make our unconscious conscious; we need to build the strength to reflect on our inner world on a constant basis.

In another fairy tale, The Snow Queen, the mirror distorts the appearance of all things, reflecting only the ugliness. Upon carrying a mirror, the trolls end up breaking it into pieces, some of which end up falling to the human world and into the eyes and heart of a boy named Kai. Kai becomes cold-hearted and starts to only see the ugliness in everything. The Queen kisses Kai twice and brings him to her palace where he lives among the trolls with satisfaction. The Queen then tells Kai that if he spells "eternity" with the pieces of a frozen lake called "Mirror of Reason," she would grant him freedom. Gerda approaches Kai, who is unable to perform the task given to him, but he does not recognize her. Gerda's warm tears melt the mirror pieces embedded in Kai; as if waking from a dream, Kai recognizes Gerda and they both return home.

The mirror in this fairy tale also reflects the reality: a distorted reality. Hence, when the mirror shards are embedded in his eyes, Kai begins to lose himself. The mirror represents 
the mirror of trauma. Kai is unable to recognize his emotions and gradually becomes cold. $\mathrm{He}$ only sees the distorted reality and ends up getting trapped in the Winter Palace. As mentioned before, depending on the light, position, and curvature of a mirror, reality becomes distorted to some extent. We may in fact never know how we really look like throughout lifetime. Some people will never recognize their personas as their true selves throughout their lifetime. If the ego is identified with the persona, one cannot realize his or her emotions and hence is unable to express them to others.

In modern days, this phenomenon can be explained through mirror neurons. The process of looking at a reflection in a mirror and becoming aware of oneself is also a way to understand and empathize with others. Neurobiological studies on mirror neurons support this part of the development of the human psyche (Iacoboni, 2009). Mirror neurons, as the name itself suggests, are neurons involved in the understanding of others' experiences through one's own. Upon observing others' emotions and actions, mirror neurons run simulations based on one's own similar experiences. By becoming conscious of similar experiences, one comes to understand what others are feeling. Ultimately, the mirror symbolizes the act of understanding others by becoming conscious of them (Iacoboni, 2009).

When we identify with a persona that has been adjusted to societal standards and try to hide our immature and inferior shadows, various emotions are oppressed, we cry on the inside (Sung, 2015). Our real ego is trapped behind our persona - just like Kai who, with mirror shards embedded in his eyes, is trapped in the Winter Palace. The mirror shards in Kai's eyes melt when he meets Gerda, his female friend, and recognizes his true anima. In other words, Gerda helps turn the mirror of trauma into a mirror of positivity. Through Gerda's tears, Kai becomes aware of some aspects of himself and starts his journey towards individuation. Gerda is the anima aspect of Kai's shadows. When his heart turned cold and his emotions got lost, he lost his feminine aspect also. Recognizing our shadows helps heal our emotions (Sung, 2015). 
Journal of Symbols \& Sandplay Therapy, Vol.9 No.1.

\section{Mirrors in Classic Literature}

Mirrors are used for various functions in literature: as something that reflects objects, as a door leading to a different world, a means for self-reflection, and many more. The following is an excerpt from Michael Ende's Mirror in the Mirror:

He stood, waiting, cross-legged with one foot tip-toed and the other placed flat on the ground, bis right hand hanging in the air and the left lightly placed on his waist. At times when the pain of this posture was unbearable, he shifted to a position that is an inversion of his previous posture; that is, as if mirroring the image of bimself reflected in a mirror.

In this short story, the protagonist loses his true self as he identifies with himself in the mirror. Those who have lost their true selves are only conscious of how they are seen by others and act accordingly. They end up falling into a sense of inferiority when their actions are not acknowledged.

The following poem is Mirror by Yi Sang:

In the mirror, there is no sound.

There may never be a world as quiet as that.

In the mirror, I have ears.

I have two pitiful ears that do not understand my words

The me in the mirror is left-handed

A left-handed person who doesn't know how to receive my handshake - a left-handed person who doesn't know handshakes

Because of the mirror, I cannot touch the "me" in the mirror

But if it wasn't for the mirror, I would not have met the "me" in the mirror 
Yeo Reum, Lee / Symbolism of Mirrors as the First Step of Individuation and Self-Awareness

Even though I don't have a mirror right now, the "me" in the mirror is always in the mirror

I do not know well, but I'll be preoccupied with my lonely business

Although the "me" in the mirror is quite my opposite

We are quite alike

It is a pity that I cannot be concerned for and examine the "me" in the mirror

In this poem, the mirror is represented as a symbolic object used to look into one's ego. The poem talks about two types of egos: the inner ego existing within the mirror, and the real ego outside of the mirror. The "real me" and the "reflected me" in the mirror are depicted as identical but different. Through this paradox we are able to verify the differentiation of the ego and discovers the genuine aspect of the ego. The mirror could be a symbol that represents the power of the unconscious that objectively reflects an individual (Jung, 1964/1966). In other words, it could be said that the ego outside the mirror is the conscious ego and the ego within the mirror is the unconscious ego; this poem speaks of the process of integration of both egos.

The mirror also appears in Yun Dong-Joo's Confessions and Seo Jeong-Ju's Beside the Chrysanthemum. The following excerpts are parts in which a mirror is mentioned:

\section{- From Confessions -}

Of what dynasty

Could the tarnished green copper mirror be a relic

That my face lingering within it

Brings on such disgrace.

- From Beside the Chrysanthemum -

Oh, Chrysanthemum, looking like my elder sister,

who stands in front of her mirror 
Journal of Symbols \& Sandplay Therapy, Vol.9 No.1.

after a long journey through the back alleys of her youth,

her heart tightened by her longings and regrets.

The mirror in both poems signifies self-examination, in which one recognizes himself or herself in the mirror and reflects on himself or herself. The mirror calls about thoughts of oneself; humans can see with this point of view (the confusion experienced when shock is brought to consciousness) only through the unconscious (Jung, 1964/1966). Both poems show introspection of the past self by looking at the current self through a mirror. By being able to look at oneself, one can find their way back to oneself and realize his or her true inner self.

\section{MIRRORS IN SANDPLAY THERAPY}

This client was a 15-year-old girl. Her mother passed away when she was seven. She did not live with her father; he lived with her stepmother and her younger siblings. She used to live with her grandmother, aunt, uncle, and other relatives but, at the time of therapy, she was living in a child welfare institution where her aunt works. She wore more earrings, necklaces, and other fashion accessories than the other girls staying in the institution. She struggled with traumas from an earthquake and health problems. When asked about details of her family, she replied with an "I don't know" and was quick to change the subject.

During the first session, she put a mirror in the left side of the sandtray. She said

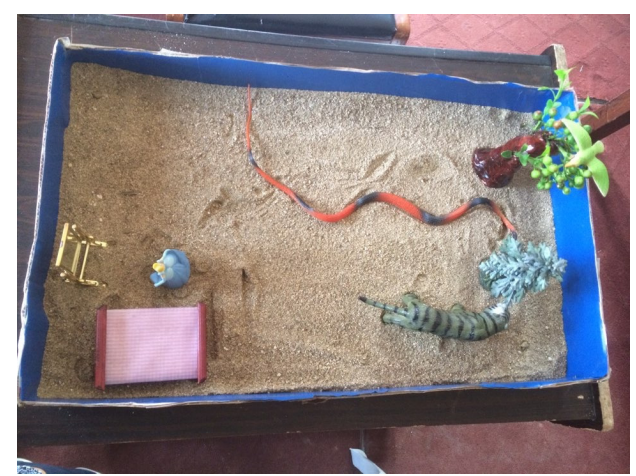

Fig. 3. Sandpicture of a 15-year-old Nepali girl 
that she liked mirrors and the woman standing in front of the mirror was herself. Her description of the sandpicture is as follows:

"She (the female figure in front of the mirror) loved a tiger. One day, she was walking down the road and was attacked by a snake. The tiger and the snake fought, and the tiger got burt and eventually died. She was very sad. She began to cry, and the birds in the forest cried with her."

The client added that the woman looked very sad and lonely. The client looked at the mirror, and spoke more about the female figure:

"I think she's looking at the mirror and asking 'Mirror, mirror, on the wall, who's the fairest of them all?' She wants to be beautiful, so she asks the question to the mirror every day."

The client didn't have the opportunity to have her own space after her mother died as she lived with her relatives or at the institution. This situation allowed her persona to continually become stronger. Just as the beauty-seeking female made daily queries to the mirror, the client, who never had the time to concentrate on herself, could not help but to focus on how she would look in front of others every day. The tiger, which fought with a snake, symbolizes the sky and the power of the sun (Cooper, 1978). The sun (light) is an essential element for a mirror, as mirrors reflect objects through light. However, the tiger is killed by the snake. So even when the female figure looks at the mirror, the mirror cannot function properly without light, which signifies that the positive self-perception of the mirror is lost and the client is trapped in her personas.

The next sandpicture was created by a young woman aged 23. This client had experienced somatization syndrome, depression, anxiety, and trouble with interpersonal relations since her childhood years. She came to therapy as she was having trouble with building relationships with her coworkers. The client divided the sandtray into two sections: near and rear. In the near part of the sandtray she placed an angel, beautiful things, fruits, and other objects she liked. Then she explained that that people in the rear part of the tray are those 
Journal of Symbols \& Sandplay Therapy, Vol.9 No.1.

had committed sins and hence were being dragged away. Their sins included harassing and killing women and children, mercilessly murdering their parents, and encouraging bullying. A mirror was placed in the left rear section of the sandtray. According to the client, this mirror reflected the sins of the criminals so they could see what they had done.

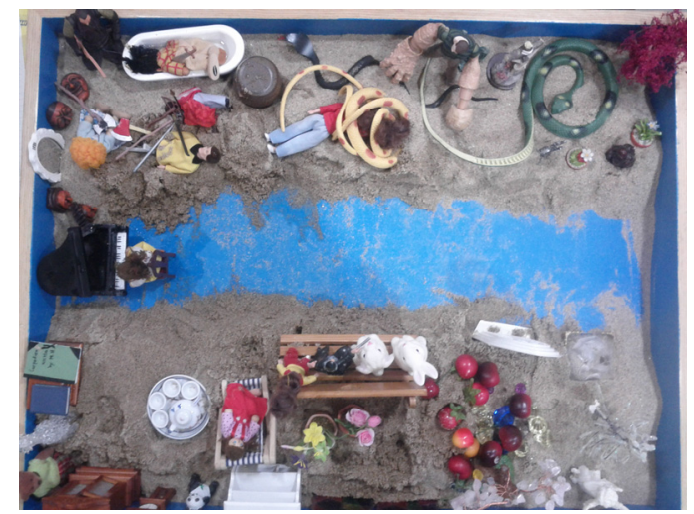

Fig. 4. Sandpicture of a 23-year-old woman (Jang, 2017)

Believing that the cause of her traumas was external, she set a scene where the criminals had to watch themselves being punished, as if she was carrying out revenge against people around her in reality. However, the mirror also signifies the need to reflect on herself; she ought to realize that the culprit behind the oppression and anguish was within herself. Her childhood anxiety and trauma developed an archetypical defense mechanism in her psyche, which hindered her adaptation to everyday life. Just like Kai in The Snow Queen, the client's trauma impeded her from seeing her inner world, which caused difficulties for her in the outer world. In order to achieve a balance between her inner and outer worlds, the client must be able to explore our inner world. Only by facing her inner shadows and integrating both positive and negative aspects can she reach self-completion - in other words, individuation. The new energy that she gains through this process will become a driving force for her to adapt to the outer world as well as explore other aspects in her inner world. 


\section{Conclusion}

Humans must display their persona while living amongst others. Personas used towards family, friends, and coworkers all differ. It does not mean, however, that these personas are not a genuine representation of oneself. Personas are in fact a genuine aspect of oneself, albeit a false ego created by the true ego. Sometimes we concentrate too much on the outer world that we forget our genuine ego; we live life believing that our false ego is the real one. Miller called the people who live with their false ego as having "as if" personality. If the real ego loses its place, we lose our ability to recognize our own emotions and naturally lose the ability to convey our emotions to others. The real ego is no longer able to develop or become differentiated, making us lose the energy that helps us explore our inner selves, hence losing sight of ourselves. Mirror is a good symbol of this phenomenon. While the mirror is a symbol of wisdom, enlightening us by reflecting our true selves, it also distracts us from seeing our true selves when we get stuck inside of it.

Through the positive aspect of the mirror, we can move towards individuation, which is a process of self-awareness. Self-awareness is the process of realizing the elements of the unconscious; such realization is not only an intellectual one, but also a process of being “enlightened" through emotional insight (Seong, 2015). By consciously reflecting on ourselves and thus finding the balance between our inner and outer worlds, we come to be able to take care of both worlds. According to Jung's book Mysterium Coniunctionis, it seems that the ego-consciousness confronts itself in a relationship of symmetrical projection and the ego, as a complex that could made conscious, must be able to differentiate subject from object and therefore become a definite entity (Franz, 1972).

Bringing the unconscious to consciousness is not an easy task. It requires going through the process of differentiating ourselves from our personas, and recognizing and integrating the shadows and the anima (or the animus). To do this, we need to be aware of true ourselves, for which some internal work is needed to act as a positive mirror. 
Journal of Symbols \& Sandplay Therapy, Vol.9 No.1.

\section{References}

Atsuhiko, Y., \& Noriko, F. (1996). Nihon No Sinwa Densetsu. Tokoy: Seidosha. (Trans. into Korean in2005)

Bärbel, W. (1991). Weiblicher Narzißmus. Munich: Kösel-Verlag. (Trans. into Korean in 2006)

Boa, F. (1988). The way of the dream. Toronto: Windrose Films Ltd. (Trans. into Korean in 2004)

Cho, B-H. (2006). Child development. Paju: Kooyookbook

Choi, J-E. (2005). Animal - monstorum - emblems: Knowledge and symbol of the middle ages. Seoul: Humanist.

Cooper, J. C. (1978). An illustrated encyclopaedia of traditional symbols. New York: Thames \& Hudson. (Trans. into Korean in 2012)

Ende, M. (1994). Der Spiegel Im Spiegel. Stittdart-Wien. (Trans. into Korean in 2008)

Eugen, D. (1981). Das Madchen obne Hande: Marchen Nr. 31 aus der Grimmschen Sammlung.

Olten: Walter Verlag. (Trans. into Korean in 2003)

Franz, M. L. (1972). C. G. Jung-Sein Mythos in unserer Zeit. Verlag Hans Huber, Frauenfeld.

Han, O-S. (2016). Analysis of the psychological understanding of Hermann Hesse 's work.

Korea Jung Analyst Association public lecture materials book, 62-67.

Iacoboni, M (2008). Mirroring people: The new science of how we connect with others. New York:

Picador. (Trans. into Korean in 2009)

Jang, M-K. (2017). Analytical psychological sandplay therapy. Seoul: Hakjisa.

Kim, M-R. (2015). Korean Language an Etymological Dictionary. Seoul: Chisik kwa Kyoyang..

Korea Creative Content Agency. (2007). Cultural contents. http://www.culturecontent.com/

Kwak, C-H. (2003). The Buddhist prior. Seoul: Sigongsa.

Kwon, S-M. (2014). Basics of abnormal psychology. Seoul: Hakjisa.

Lee, B-Y. (1998). Analytical psychology; C.G. Jung's thoughts on mind. Seoul: Ilchoak.

Lee, Y-B. (2003). God's kingdom, human kingdom; The world of myths. Seoul: Dusandonga.

Sung, E-K. (2015). Tears: Symbol of healing towards the individuation. Journal of symbols \& sandplay therapy, 6(2), 47-60. 
Yeo Reum, Lee / Symbolism of Mirrors as the First Step of Individuation and Self-Awareness

The Korean Association of literature Critics (2006). Glossary of cultural criticism. Kookhak.

Yi, S (2001). The completed works of Yi Sang Literature. Paju: Literature \& Thought.

Received : April 30, 2018

Revised : June 18, 2018

Accepted : June 20, 2018 